This item was submitted to Loughborough's Institutional Repository (https://dspace.lboro.ac.uk/) by the author and is made available under the following Creative Commons Licence conditions.

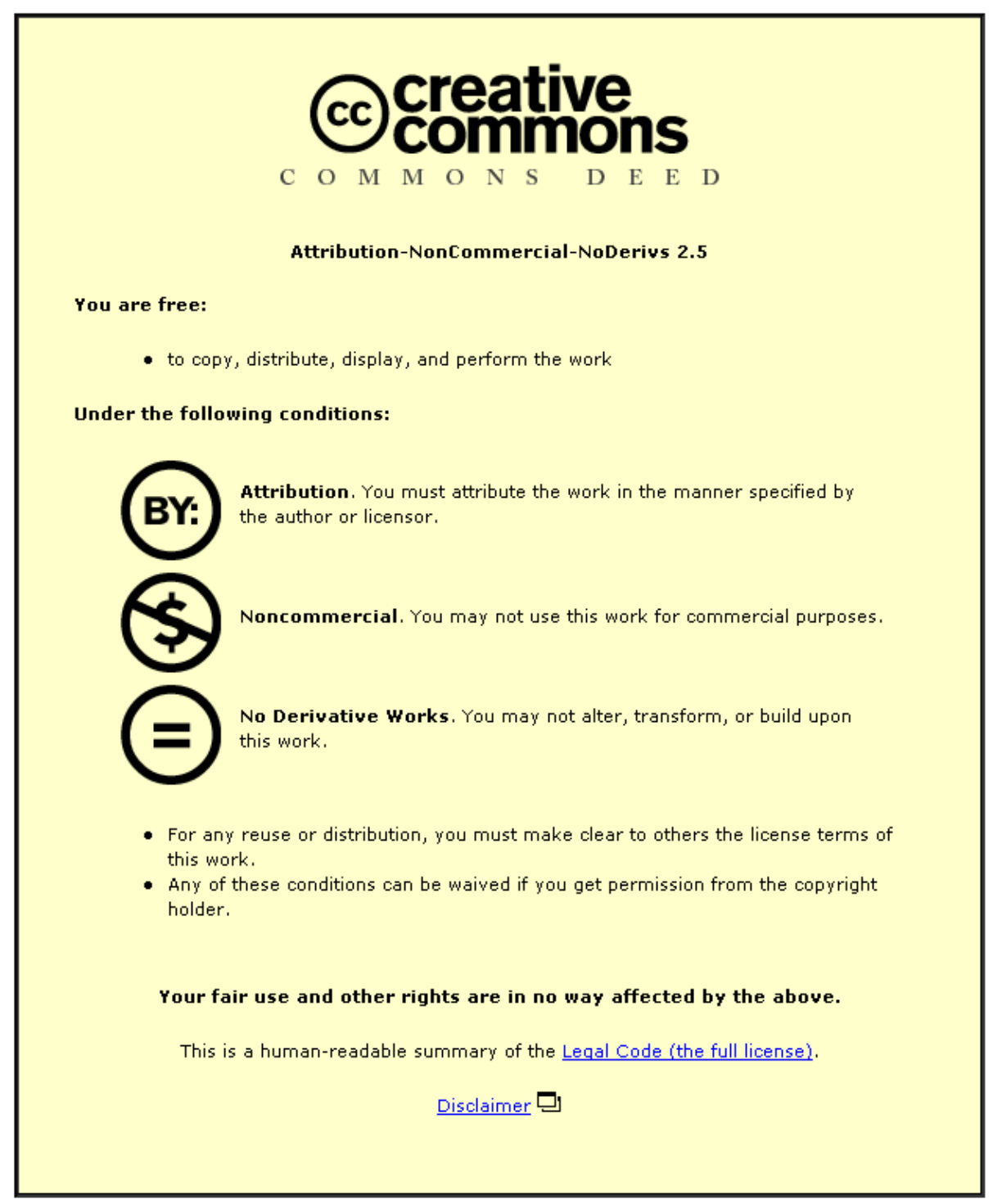

For the full text of this licence, please go to: http://creativecommons.org/licenses/by-nc-nd/2.5/ 


\title{
UK LOCAL AUTHORITY ATTITUDES TO PARK AND RIDE
}

\author{
Stuart Meek*, Marcus Enoch and Stephen Ison
}

\begin{abstract}
Although the implementation activity within UK local government would suggest that bus-based Park and Ride $(\mathrm{P} \& \mathrm{R})$ is considered popular, little evidence exists which tests this assumption empirically or explores the constituent elements of this popularity. In addition, a growing body of evidence indicates that P\&R may increase the vehicle miles travelled (VMT) of its users. This paper reports on a recent survey of UK local authorities, both with and without current P\&R provision, to understand the reasons behind its popularity and the level of recognition of its effectiveness in reducing car use. Particular consideration is given to the relationship between P\&R and conventional public transport (particularly bus) services, as the transfer of passengers from these has a significant impact on the effectiveness of $P \& R$. The potential future growth of $P \& R$ is also considered. The results suggest a number of divergences with the empirical evidence, particularly with regards the traffic effects of $P \& R$. It is strongly predicted to grow but there is support for implementing $P \& R$ in ways that may increase its effectiveness.
\end{abstract}

\section{Introduction}

Over the past 40 years, the UK has seen considerable growth in the number of bus-based Park and Ride (P\&R) schemes with over 130 current sites. P\&R schemes are not homogenous and the way in which they are implemented is dependent upon local authorities. Yet there are clear similarities that form an approximate model which helps distinguish UK bus-based P\&R from other international and model interchanges. It is implemented by local authorities and considered part of local transport strategies. Sites (car parks) are found around $4 \mathrm{~km}$ from the urban core, close to main access corridors. Sites are designed to attract the motorist with pleasant surroundings and often, on-site facilities such as waiting areas. High quality buses operate at high frequency, generally between 8 and 15 minutes in peak periods. Only one or two stops are usually made to minimise journey time.

These service characteristics have changed little since UK local authorities first experimented with P\&R in the 1960s and 1970s. Although there were some failures, P\&R in Oxford was the notable success of these experiments and it was joined by other sustained services in the 1980s. At this point, success was enjoyed mostly by distinctly historic cities such as Shrewsbury, Bath and Chester which by their nature, constrained opportunities for road access and parking development in city centres. Despite the appeal of P\&R being confined in its infancy to this type of setting, these schemes provided key demonstration effects to local authorities and indeed, the UK national government.

There was some national government recognition for P\&R in the early-1990s as a tool for traffic management (e.g. DoE, 1993; DoE/DoT, 1994). Subsequently, the newly elected Labour Government of 1997 considered P\&R to align well with their new focus on transport integration and sustainability. Emphasis had shifted, certainly within the policy itself, away from predict and provide - constructing road capacity to meet expected demand - towards managing the demand itself, a new approach ${ }^{1}$ which has fundamentally changed the transport policy environment.

The new emphasis in policy reflected well on P\&R. It was considered an effective means to deal with congestion and air pollution (DETR, 2000). Such policy clearly affects local government but there were further incentives. The financial burden of schemes was not wholly on local funds but it could also be obtained from the national government to whom local authorities submit their Local Transport Plans on a five-yearly basis for approval and a financial allocation. P\&R investment also comes from the private sector as planning applications made from developers can include agreements for contributions towards P\&R spaces because of the extra traffic induced by developments.

\footnotetext{
${ }^{1}$ In the rhetoric at least, although less so in reality (Goodwin, 1999; Shaw and Walton, 2001). Yet the decentralisation of decision making for transport, particularly to local authorities and in terms of the Local Transport Plan process and transport assessment, seems to have demonstrably shifted the structure of governance for transport.
} 
As a result of the shifting policy emphasis and local authorities' penchant for P\&R, it has since the 1990s diffused to a range of settings across the UK beyond the small historic towns in which it was first successful and there are over 130 sites now operating (TAS Partnership, 2007).

Alongside these significant developments in policy and practice, a body of research has emerged which questions the effectiveness of $\mathrm{P} \& \mathrm{R}$ in reducing car and use and its related emissions. Early work on the subject (e.g. Papoulias and Heggie, 1976; White, 1977) found that not all P\&R users were those who would otherwise, or had previously, used the car for their trip. Parkhurst (1995) and Parkhurst and Stokes (1994) added impetus to the research and showed from a survey of Oxford P\&R users that $36 \%$ had been abstracted from conventional public transport services. Essentially, this abstraction results in increased car use for access trips which are generally long compared to the bus portion of the trip. It was shown that coupled with a trip generation effect, the presumed benefits of $P \& R$ could be offset to some degree.

The government commissioned a study into the effects of P\&R (WSA, 1998) which showed that despite the alternative mode for up to $40 \%$ of its users being conventional public transport services, P\&R still reduced the vehicle miles travelled (VMT) of its users. Nevertheless, Parkhurst (1999) showed the report to have a less than comprehensive approach and when including the VMT of the high-frequency P\&R buses, three out of the eight WSA (1998) case study schemes were shown to increase the mean VMT of their users. Furthermore, neither study included the VMT of generated trips nor those abstracted from public transport, which would have been likely to result in further VMT increases. For an extensive review of this evidence and description of the development of P\&R in policy, see Meek et al (2008).

Thus, if one assumes that P\&R intends to both capture the motorist and reduce the VMT of its users, the evidence suggests that this is not the case, certainly in all circumstances. Despite this, it has continued its growth in the UK. Since 2000 for instance, over 50 new P\&R sites have been introduced. It appears then that P\&R is a popular instrument with local authorities. Yet there is a dearth of research considering the local authority relationship with $P \& R$ and their views towards it. The evidence that does exist considers $P \& R$ in the context of other transport policy options. Ison (2000) for instance found in a survey of 254 local authorities and academics that $68 \%$ of respondents considered $\mathrm{P} \& \mathrm{R}$ to be 'totally effective' or 'fairly effective' for reducing traffic congestion while in terms of public acceptability, $85 \%$ considered it 'totally acceptable' or 'fairly acceptable'.

Indeed, the gulf between local authorities' penchant for P\&R and the empirical evidence pointing to its inefficiencies has been noted in the past. Parkhurst (1995) suggested that it might be down to the inconsistent nature at which the research has been undertaken (Parkhurst was one of the first researchers to persist with the subject); or, that the benefits were 'irresistible' for local authorities (p.16) and outweighed the concerns; or, that local authorities were hesitant in committing resources to collecting the appropriate data. It may of course be a combination of these factors.

This paper presents the findings from a national survey of local authorities. It sought to understand, in light of the body of evidence that demonstrates the inefficiencies of the P\&R concept as it is currently implemented in the UK, why it has become so popular. It considers whether the implementation activity has been a result of unawareness or simply disregard of the evidence. After some details of the survey administration, the paper looks at the findings on $\mathrm{P} \& \mathrm{R}$ in the context of alternative policies in terms of effectiveness and public acceptability. It then moves to consider not only the policy goals for which P\&R is used but also the other motivations for its use; political and financial motivations, for instance, may play a role in the implementation decision. Particular consideration is given to a reportedly significant effect of $\mathrm{P} \& \mathrm{R}$ - public transport abstraction - and it looks at attitudes on the relationship between P\&R and conventional bus services. Finally, the future is considered to understand the current stage of the lifecycle of $P \& R$ and the level of enthusiasm for it that remains.

\section{Method}

The questionnaire was sent to respondents in September 2008. Each local authority with P\&R was identified from the TAS Partnership (2007) inventory of schemes. Schemes introduced since the publication of the inventory - known through the authors' knowledge and the media - were also included. The remaining UK local authorities, those with no $\mathrm{P} \& \mathrm{R}$ provision, were added to the sample, to which a slightly different questionnaire was sent, as outlined in the findings below. The responsibility for P\&R implementation and operation is largely with the transport planning level of local government, which owing to the inconsistent structure of local authorities in the UK are metropolitan districts, county-level authorities or unitary authorities. For London and 
Northern Ireland, questionnaires were sent to Transport for London and the Department for Regional Development of the Northern Ireland Assembly respectively.

The main actors within local authorities are councillors, who are elected into their positions to represent the views of the electorate in formulating policies, and officers, who are employed by the local authority to put policies into practice. Both councillors and officers were included in the survey since they would provide an overview of the thinking at both levels, both of which are important in the decision to adopt P\&R and in shaping its operation. Each local authority was contacted on the telephone to agree participation and for the details of the most appropriate officers and councillors to respond. Each participant was emailed a questionnaire with a covering letter indicating how to email it back when completed. The response rates are shown in Table 1.

Table 1 Questionnaire response rates

\begin{tabular}{llll}
\hline & Sent & Returned & Response (\%) \\
\hline Local authorities with P\&R & & & \\
Officers & 63 & 45 & $71 \%$ \\
Councillors & 63 & 17 & $27 \%$ \\
\hline Local authorities without P\&R & & & $51 \%$ \\
Officers & 124 & 63 & $18 \%$ \\
Councillors & 124 & 22 & $39 \%$
\end{tabular}

Generally, the response from council officers was much higher than from councillors. This is most likely because officers use their computers and monitor emails throughout the working day. For councillors however, emails are likely to be checked infrequently. Furthermore, the survey was administered in September 2008, which was a short time after local government elections. Thus, recently elected councillors would have been new to the transport portfolio and thus not fully aware of all of the issues, perhaps provoking some hesitance in responding.

\section{Park and Ride in relation to other policies}

To understand the appeal of $P \& R$ to local authorities requires an appreciation of its alternatives and complements. Initially the survey recorded, on five-point Likert scales, both the degree of effectiveness in reducing car use and the public acceptability that respondents associated with eighteen transport policy measures. The instruments and questions were identical for both authorities with $\mathrm{P} \& \mathrm{R}$ and those without. The intention of this exercise was to provide comparisons with P\&R. Thus, supply-side instruments were the focus although a town centre parking charge was included as, unlike many demand-side tools, it is in widespread use. It is also the most comparable alternative to $\mathrm{P} \& \mathrm{R}$ for the motorist. 
Figure 1 Effectiveness of measures in reducing car use

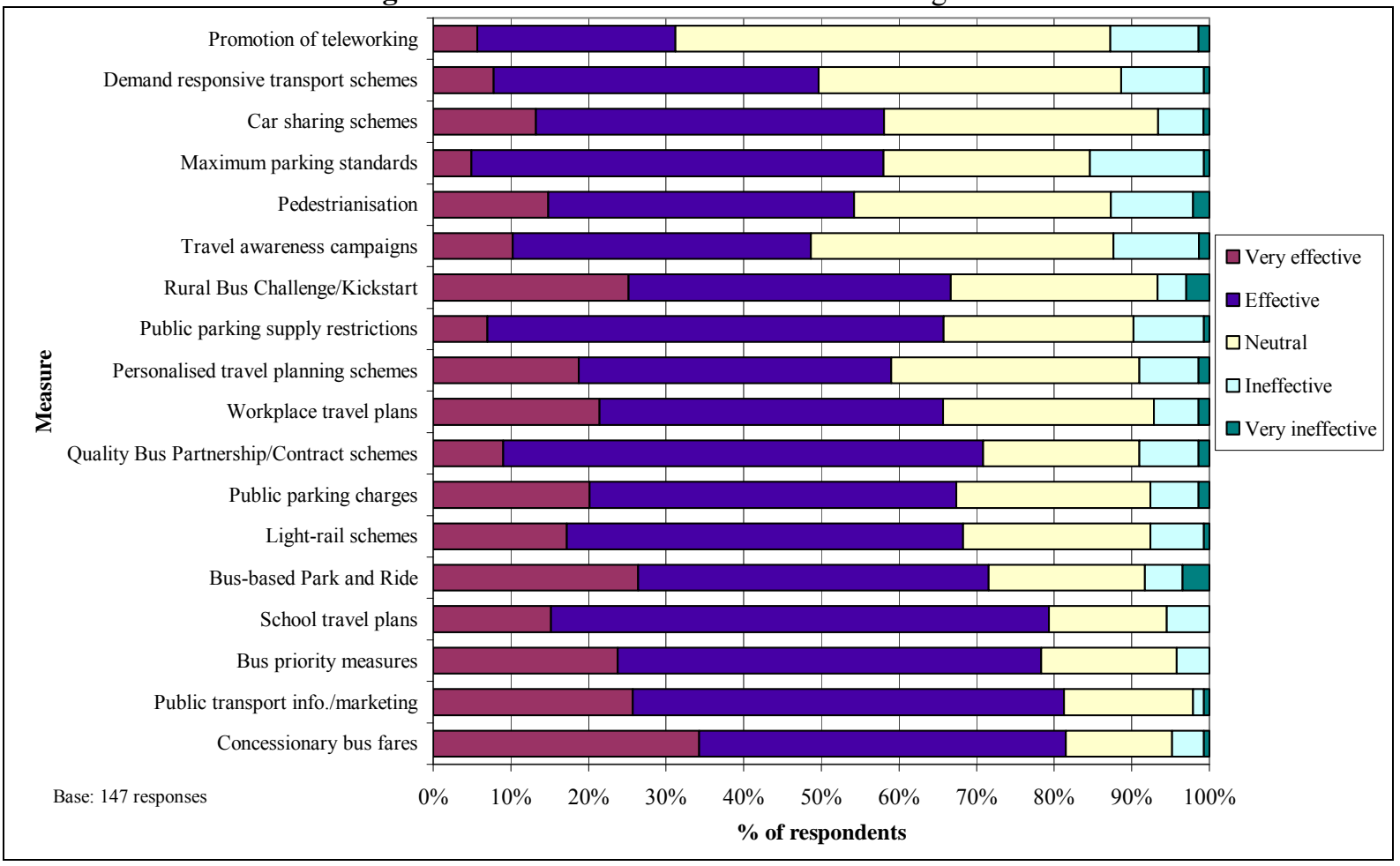

The results of these questions are shown in Figure 1 for effectiveness and Figure 2 for acceptability. The measures are shown in rank order for their aggregate scores on the Likert scale. Concessionary bus fares were considered both the most effective and acceptable measure. These were first introduced in England in 2006, enabling disabled people and those over 60 to travel on local buses free in off-peak hours. Clearly local authorities have some experience with the concessionary fare policy and by the time the survey was administered in 2008 , its effects. The favourable view is most likely down to the measure strongly encouraging bus ridership in an otherwise, in the long-term, declining market.

Other measures that directly promote public transport use - public transport information, marketing and priority measures - are also considered relatively effective (Figure 1). This can explain, at least to some degree, the favourable perceptions of P\&R. Yet it may also be linked to the issue of control, particularly for bus services. Control of services does not necessitate reductions in car use but local authorities may consider it useful in maximising effectiveness. Although the bus market in the UK is deregulated, local authorities can play a role in their provision. The Quality Bus Partnership is a good example, although this features only as the eighth highly ranked measure. P\&R does provide another opportunity though. Local authorities may subsidise P\&R bus services and can thus exert significant control over service specifications.

Demand responsive transport and Kickstart/Rural Bus Challenge schemes are ranked lower in terms of aggregate scores for effectiveness. This may be a result of limited experience of such schemes, which is an argument supported by the spread of responses. Particularly for Kickstart/Rural Bus Challenge, which was rated as 'very effective' by around a quarter of respondents, with responses at the other end of the scale offsetting its position in the aggregate ranking of scores. This may be a reflection of those experienced with the measure considering it more effective whilst those without have only general views on which to base their judgement. Experience may also have played a role with the perceived effectiveness of travel plans as those for schools, which are generally more prevalent, are rated much higher than the workplace and personalised formats. 
Figure 2 Acceptability of measures to reduce car use

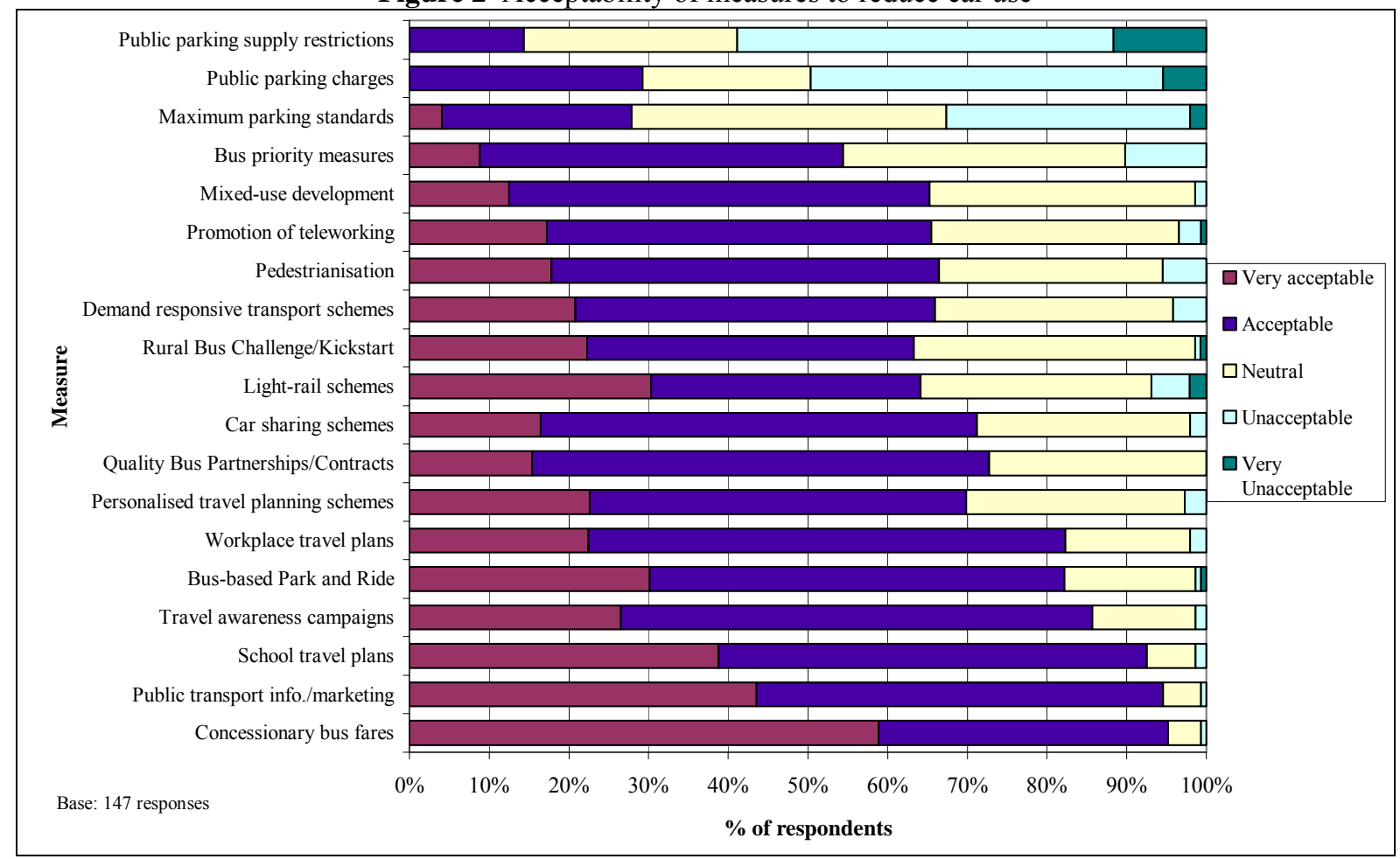

The only measure within these questions that directly utilises the price mechanism to control car use is the public parking charge. Given traditional economic notions of the effectiveness of market-based instruments, it is somewhat unanticipated that this measure was considered only the seventh effective. As would be expected, public parking supply restrictions and maximum parking standards are considered much less effective than pricing. In terms of acceptability, parking measures are ranked lowest (Figure 2), although supply restrictions are ranked slightly lower than pricing. This may be associated with inertia, as UK motorists have grown accustomed and are less sensitive to paying for parking.

P\&R is deemed to be both relatively effective in reducing car use and publicly acceptable as it is ranked fifth on both scales. While this is within the range of measures that promote public transport use, it clearly runs counter to much of the empirical work on the traffic effects of P\&R. It may be a logical deduction that transferring for part for of the trip may reduce car use. Officers and councillors may be wither unaware of the unintended byproducts of the excess VMT resulting from public transport abstraction, trip generation and the high frequency of P\&R buses, or may simply underestimate their influence on the overall traffic effects of P\&R.

To identify any relationship between perceived effectiveness and acceptability, the Spearman rho was performed to compare the responses for each measure. For most of the instruments at the $95 \%$ confidence level, a positive relationship was found, albeit generally weak (ranging from $\rho=0.34$ for workplace travel plans to $\rho=0.63$ for light rail schemes), which suggests that respondents view the measures with similar degrees of effectiveness and acceptability. This is to be expected since the measures are predominantly supply-led in their approach and their efficacy in mileage reduction terms is dependent upon their adoption. The main exception to this was the town centre parking charge where no statistically significant relationship was found. This is unanticipated, as a negative relationship would be expected given the traditional economic view that measures utilising the price mechanism are relatively effective yet unacceptable compared to supply-side instruments. 
Figure 3 The acceptability of P\&R by respondent segment

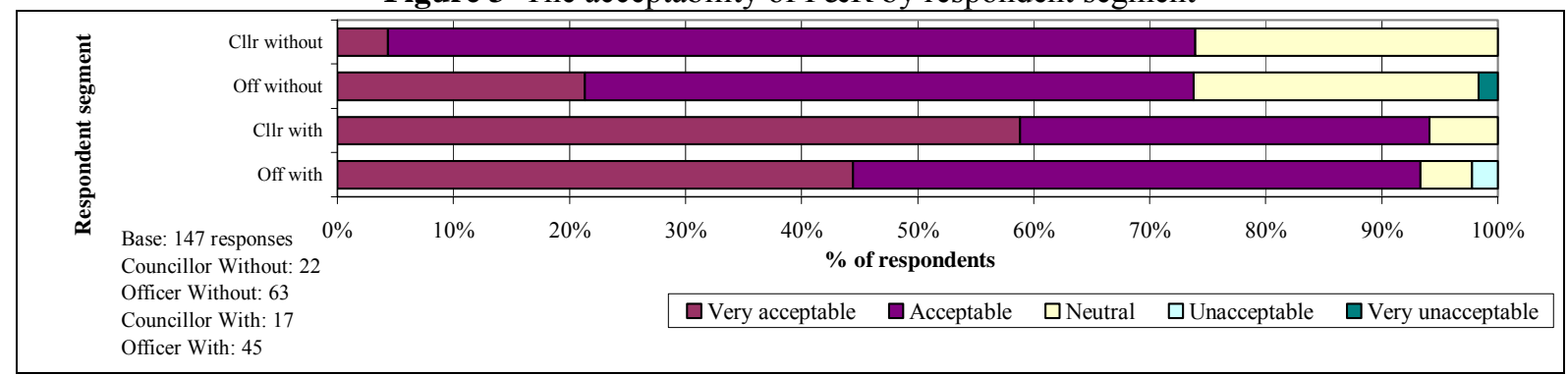

Figure 4 Effectiveness of measures with significant differences across respondent segments

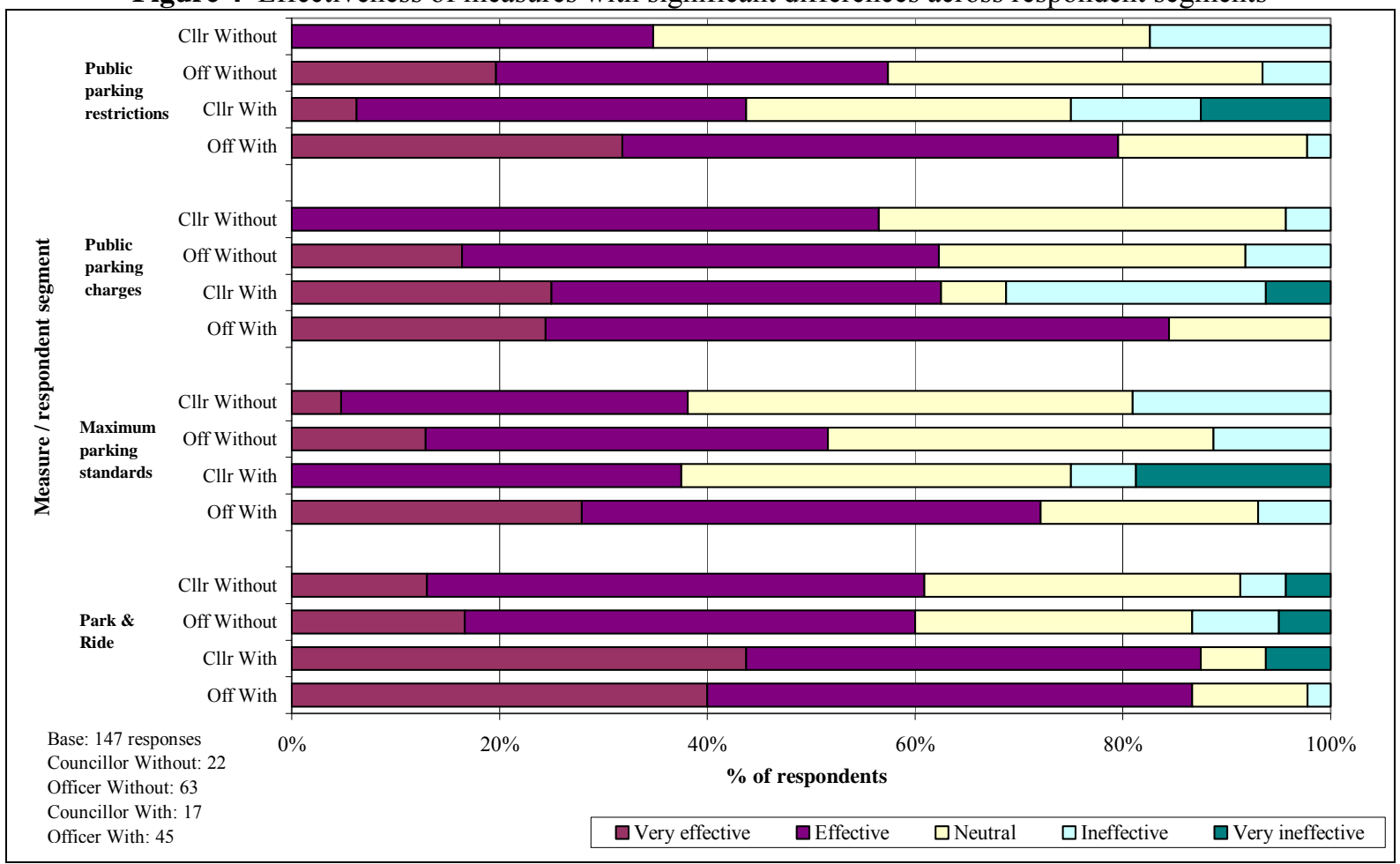

All respondents were asked the same questions on effectiveness and acceptability. To determine differences in responses across the four subsets, officers and councillors with P\&R in their authority area and those without, the Kruskal-Wallis analysis of variance was used. It revealed that at the $95 \%$ confidence level, there was no statistically significant difference for most of the tested transport measures. For acceptability, there was a difference across the segments for only P\&R, the results of which are shown in Figure 3. This is somewhat unsurprising given that authorities with $P \& R$ are likely to view it more favourably that those without.

For effectiveness in reducing car use, there was a statistical difference across segments for P\&R, maximum parking standards, public parking charges and public parking supply restrictions (Figure 4). Councillors held a weaker view of effectiveness of these measures, particularly for the councillors without P\&R. This may be attributed to the role of the councillor as an elected representative of the public thereby perhaps more closely associating effectiveness with acceptability, whilst the officer will theoretically possess the expertise to be more conversant with technical notions of traffic reduction.

\section{Policy goals and motivations}

As stated above, national government policy on P\&R shifted in the 1990s following fundamental changes in transport policy thinking. The focus for P\&R moved away from parking capacity expansion, towards sustainability and reductions in congestion and air pollution (DETR 2000). Although policy goals had altered, the concept of P\&R remained unchanged. The empirical evidence has shown however, as outlined above, that P\&R has a minimal or counter-productive effect on some of these goals. The survey sought to understand, given the evidence and national government policy, the degree to which these views are shared by local authorities. For 
local authorities with $P \& R$, data collected by the survey on the relative importance of a range of policy goals for the implementation of P\&R are shown in Figure 5.

Figure 5 Importance of policy goals in P\&R implementation

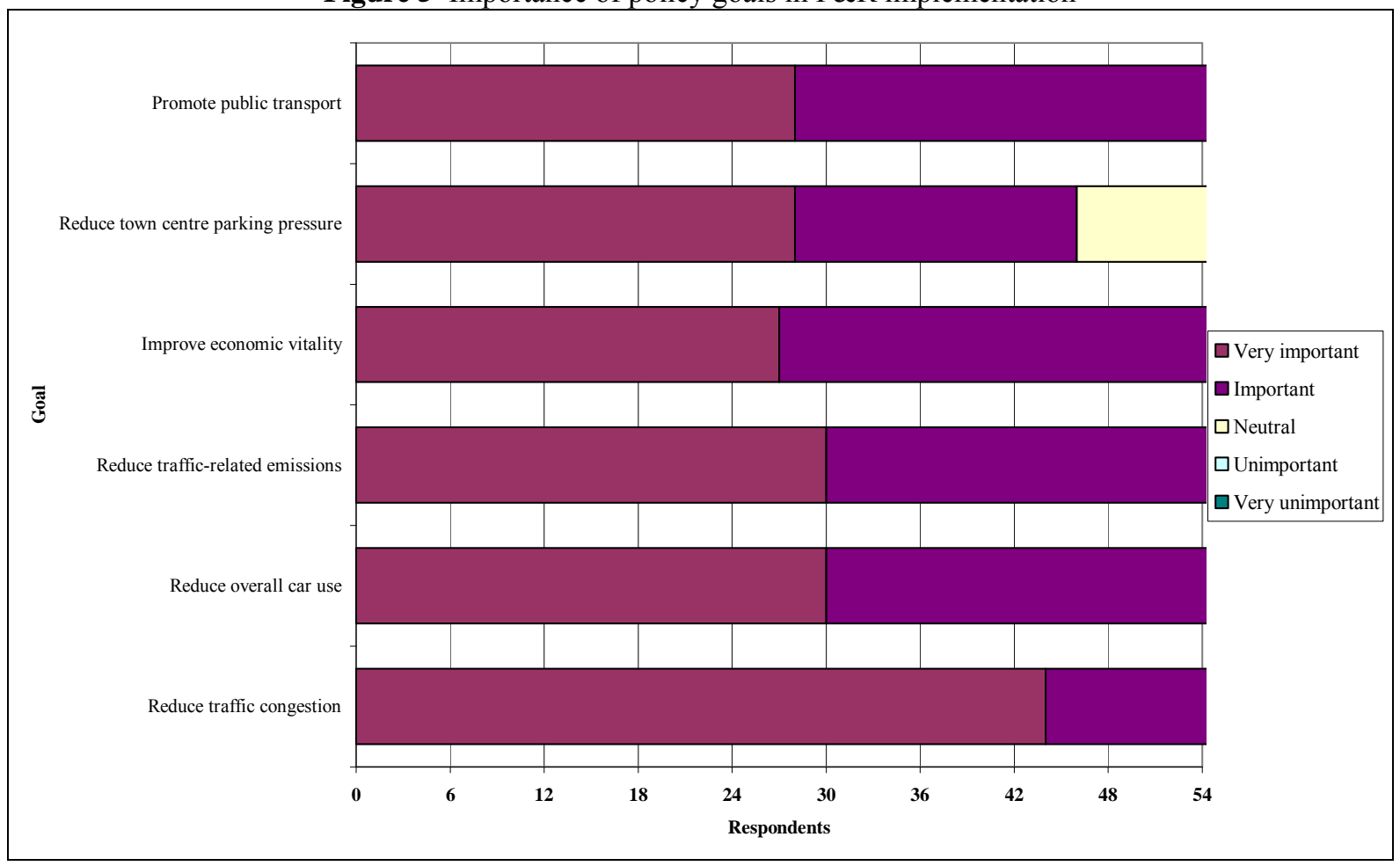

Clearly, P\&R is used for a range of policy goals. Very few responses indicated that any of the policy goals were unimportant or very unimportant. Reductions in traffic congestion are the key goal for which P\&R is used but others relating to sustainability, reducing car use and traffic related emissions, are also generally considered important. These goals are in accord with national government policy. Yet it is somewhat surprising that the goals most likely to be economically beneficial to local authorities, encouraging economic vitality and reducing parking pressure, are seen as slightly less important. Furthermore, whilst the evidence, as outlined above, suggests that P\&R has a negative effect on conventional public transport services, this data shows that $P \& R$ is considered as having a favourable impact by respondents.

Policy goals are the specific outcomes for which P\&R is used. A line of differentiation should be drawn between these and motivations for local authorities. A motivation may be implicit and involve, for instance, political concerns or the reputation or image of the local authority. Table 2 shows data on the importance of a range of motivations to local authorities. Local authorities with P\&R were asked specifically about the motivations for its operation. Local authorities without P\&R were asked a similar question but this was based on supply-side transport measures in general. This was done to evaluate the degree of similarity between P\&R specific motivations and those for other measures.

Table 2 Importance of motivations to introduce P\&R

\begin{tabular}{lllll}
\hline Respondent segment & \multicolumn{2}{c}{ With P\&R (\%) } & \multicolumn{2}{c}{ Without P\&R (\%) } \\
Importance & $\begin{array}{l}\text { Very / } \\
\text { important }\end{array}$ & $\begin{array}{l}\text { Very / } \\
\text { unimportant }\end{array}$ & $\begin{array}{l}\text { Very / } \\
\text { important }\end{array}$ & $\begin{array}{l}\text { Very / } \\
\text { unimportant }\end{array}$ \\
\hline $\begin{array}{l}\text { Authority is seen to be tackling traffic problems } \\
\text { Authority is seen to be encouraging economic }\end{array}$ & 93.5 & 0.0 & 95.3 & 1.2 \\
$\begin{array}{l}\text { vitality } \\
\text { Potential to access private sector funding }\end{array}$ & 87.1 & 0.0 & 100.0 & 0.0 \\
$\begin{array}{l}\text { Potential to attract national government funding } \\
\text { Fits with national government policy }\end{array}$ & 51.6 & 19.4 & 82.4 & 2.4 \\
$\begin{array}{l}\text { Generates revenue } \\
\text { Helps ease the introduction of other transport } \\
\text { measures }\end{array}$ & 17.7 & 11.3 & 94.1 & 0.0 \\
\hline
\end{tabular}


Perceptions of the local authority are highly significant. An action by the local authority, particularly within the transport domain which has widespread impacts, influences the perceptions of the electorate. The electorate of course have democratic control over the political governance of the authority, namely the councillors elected into their posts who formulate policies. It is perhaps unsurprisingly then that both segments of respondents considered perceptions of action on promoting economic vitality and against traffic problems key motivations. These two motivations showed the greatest degree of similarity with the others being much more disparate.

It is generally beneficial for a local authority to formulate transport policies which align with those of the national government. Local authorities submit their Local Transport Plans (LTPs) every five years to the government, on which their performance is monitored and funds allocated. The survey reveals that whilst it is considered a significant factor for transport measures generally, it is much less so for P\&R. This perhaps indicates that $P \& R$ is primarily considered a local authority concern. Indeed, the national government have had limited involvement with P\&R, certainly at the policy level, before and since the 1990s. This is also reflected by the motivation to attract government funding which is also tied in with the LTP process.

Similarly, motivations to attract private sector funding appear to be less important for P\&R than transport measures generally. This is somewhat unexpected since private sector contributions are often used for $P \& R$ (Meek et al, 2008). Instruments such as Section 106 agreements for instance require developers to pay for $P \& R$ provision in lieu of their developments parking requirements. Of course, it may be the case that this funding source is not significant. Alternatively, it may not feature as a motivation to P\&R but come as later as a part of its implementation.

The low level of importance placed on $P \& R$ as a revenue stream is expected since few are known to generate any significant revenue if at all. Perceptions of revenue generation for measures generally may reflect the desire of local authorities to hypothecate funds for transport projects or other areas.

A high level of importance was placed on P\&R for easing the introduction of other measures. Given the supplyside nature of $P \& R$, its use as a 'carrot' to be used alongside 'stick' measures which seek to control demand is to be expected. For instance, P\&R may be used alongside stringent town centre parking controls or charges to create a visible transfer of spaces rather than a simple restriction. Clearly, this motivation was inappropriate for transport measures generally.

In addition to these motivations, local authorities without $P \& R$ were asked if it had been used in the past or considered, as shown in Figure 6. Even with local authorities without P\&R, it seems like a popular policy option with $80 \%$ of respondents indicating that it is currently in local authorities' plans or it is possible for the future. Although indicating that it is possible for the future does not provide any strong indications, these responses can be considered as reflecting favourably on P\&R. This response from such a large proportion of respondents is somewhat unexpected. Although $P \& R$ has become widely successful in a range of settings relatively recently, its success initially was confined to small historic towns, and the most successful schemes are still likely to be found in such settings. It would thus be expected that there would be more hesitance over its suitability.

To those respondents that indicated that $P \& R$ had been considered but rejected, of which there were only 13 , a further question was posed on the reason for its rejection, which allowed respondents to select all the reasons that they considered appropriate. Ten of the respondents indicated that P\&R was unsuitable for their setting while seven put it down to $P \& R$ inducing inadequate results and six perceived there to be insufficient funding available. 
Figure 6 Experience with $P \& R$ of authorities without current provision

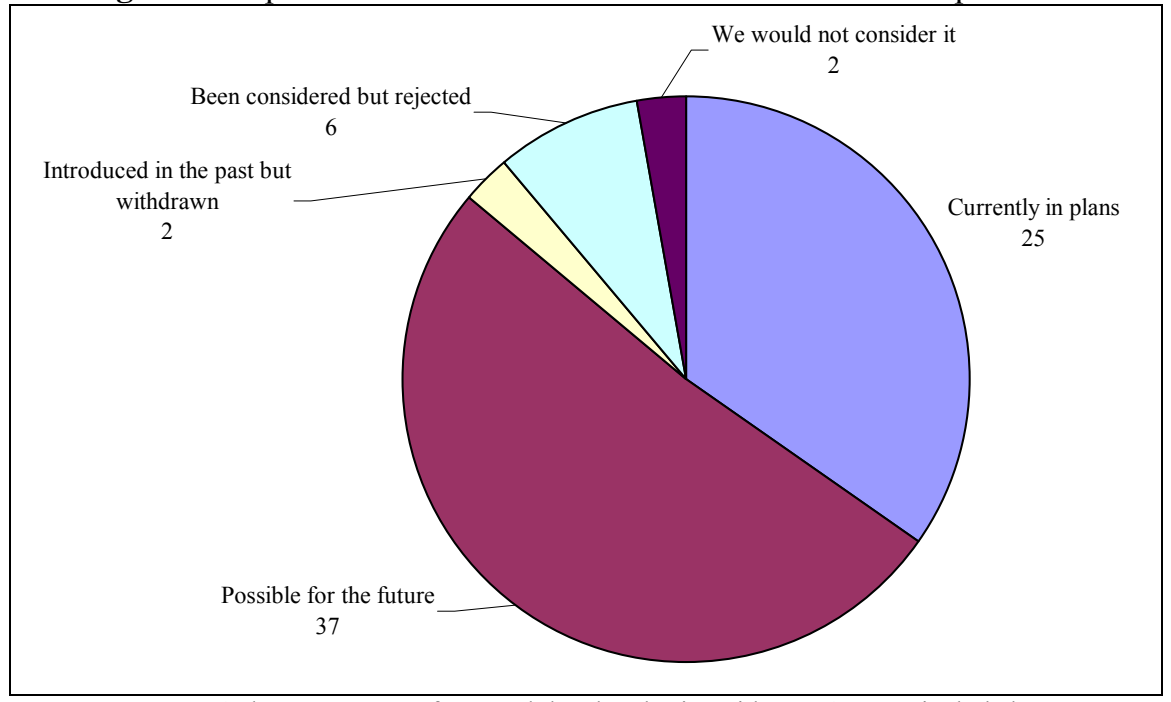

Note. Only one response from each local authority without P\&R was included.

\section{The relationship between $P \& R$ and conventional public transport services}

As stated earlier, abstraction of passengers by P\&R from conventional public transport services stimulates generated mileage. This encourages modal shift to the car for access trips, which when considering the edge-oftown location of almost all P\&R sites, is the largest portion of the complete P\&R trip. Rail services can suffer but it is to local bus services that $P \& R$ offers the most direct competition. Unlike most bus services, $P \& R$ can be subsidised through public funds from local authorities and statutory private sector contributions. So as well as a price differential, $P \& R$ can operate to high service specifications in terms of frequency, reliability and quality. Indeed, it is these tools that are used to draw the motorist. While P\&R and conventional services may be thought of as serving difference markets, the evidence on abstraction suggests that this is not always the case. Of course, there is some degree of commonality between the motorist and bus user and the service offered by P\&R will appeal to both.

To councillors and officers from local authorities with $P \& R$, questions about the interaction between P\&R and conventional bus services were posed. Data were collected on the amount of routes where P\&R and conventional bus services are duplicated and if the tickets for the two types of service are interchangeable. The results of these questions, shown in Table 3, suggest that there is considerable overlap of services and they are in most cases operated independently. Duplication of stage services may trigger bus users, albeit those with car access, to switch.

Table 3 Duplication and integration of P\&R and conventional bus services

\begin{tabular}{lc}
\hline Duplication of P\&R/conventional bus service routes & \\
\hline Duplication on all routes & $32(60 \%)$ \\
Duplication on some routes & $18(34 \%)$ \\
No route duplication & $3(5.7 \%)$ \\
\hline Integration of P\&R/conventional bus service ticketing & $4(7 \%)$ \\
\hline All tickets are interchangeable & $14(26 \%)$ \\
Some tickets are interchangeable & $35(66 \%)$ \\
No tickets are interchangeable & Note. Only one response from each local authority was included.
\end{tabular}

The level of integration also appears low. Integrated ticketing would allow the stage service user to enjoy the benefits of the P\&R service without using the 'park' element and may even stimulate bus ridership over the long-term. Still, to fully exploit this opportunity P\&R services would need to not limit themselves to short interurban routes with limited access and egress points. Yet even with current schemes, there is at least scope to improve the situation by limiting abstraction.

Although current practice indicates both the duplication and integration of services reflect negatively on conventional bus services, these are only mechanisms that may encourage abstraction and exclusion of 
conventional bus users from P\&R services. Data was also therefore collected on the feelings of respondents from local authorities with P\&R towards the effects of P\&R on bus services, shown in FIG XX. It is clear that there is a generally positive view towards the P\&R-stage service relationship. There is a strong gravitation towards disagreement for the statement "P\&R removes passengers from bus services", with over $69 \%$ holding a view of neutral or below. There was overall agreement that P\&R enhances the image of stage services, with no responses below neutral.

Figure 7 The effect of P\&R on conventional bus services

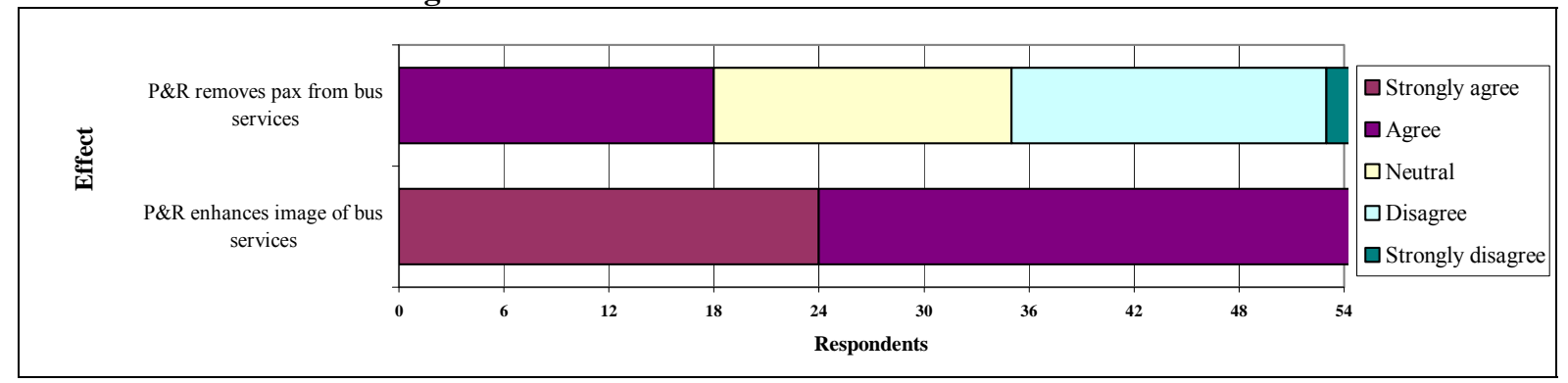

The attitudinal data may be thought of as somewhat contradictory to those on the duplication and integration of services and the previous research on the VMT effects of P\&R. Of course, it is not implausible that P\&R enhances the image of bus services. In previous research by the authors (Meek et al, 2009 - JTG Paper) it was suggested that P\&R may induce the first steps in attracting car users to public transport. Running counter to this argument are the quality differentials offered by P\&R meaning that model switch may not occur beyond the P\&R service. Besides, this effect is likely to be offset by transfer in the other direction through public transport abstraction. The feelings of the majority of respondents however indicate that this is not the case. It could be that the effects of $P \& R$ in the general sense have shifted over time, owing to changing attitudes towards the environment or increases in fuel prices for instance. Admittedly, most of the research on the VMT effects of $\mathrm{P} \& \mathrm{R}$ is rather dated. Alternatively, it could be that the markets and effects of P\&R are poorly understood by policymakers and officials.

\section{The future}

In the infancy of UK P\&R and with the exception of a few failed schemes, interest in its implementation cam from local authorities in distinct settings; small historic cities. It remains that P\&R will not be a universally attractive option, but it has nevertheless enjoyed appeal that is much more widespread, particularly since the 1990s. Policies become fashionable and diffuse as a result of the demonstration effects provided by others. They may be thought of as having lifecycles in a fashion akin to a product lifecycle. To help understand, in these terms, the stage of maturation of UK P\&R, the survey collected data on how respondents felt P\&R provision would change in the future. For authorities with $P \& R$, a question was posed on the changes in local $P \& R$ provision over 5-10 years (Figure 8). A further question on expected changes in provision at the national level was posed to all authorities in the sample. There was no statistical significant difference across the segments so all responses are shown in Figure 9.

The overall picture looks optimistic for the future growth of $\mathrm{P} \& \mathrm{R}$ provision. For local authorities with $\mathrm{P} \& \mathrm{R}$, expansion of service sis considered likely. Previous trends for P\&R development have been for authorities to establish a single P\&R site for a host city then, after its proven success, add sites incrementally to the scheme. This is highlighted in the results by over $60 \%$ of respondents considering expansion in this manner very likely and the remainder, likely. This is however, only an indicator for the existing schemes. Yet the number of schemes within authority areas also shows strong predicted growth. From this, the number of UK cities being served with P\&R would be anticipated to increase, although this only reflects authorities with established P\&R services.

In terms of the provision of services at existing sites, responses were slightly less enthusiastic about expansion but still generally optimistic. $89 \%$ of respondents for instance considered the expansion of existing sites likely or very likely. In isolation, this factor clearly has benefits of scale for bus services and may be beneficial for load factors and thus, VMT per user. Mitigating such benefits however, is the view that bus frequencies are also likely to increase which is considered likely or very likely by $96 \%$ of respondents. 
Figure 8 Expected changes in local P\&R provision

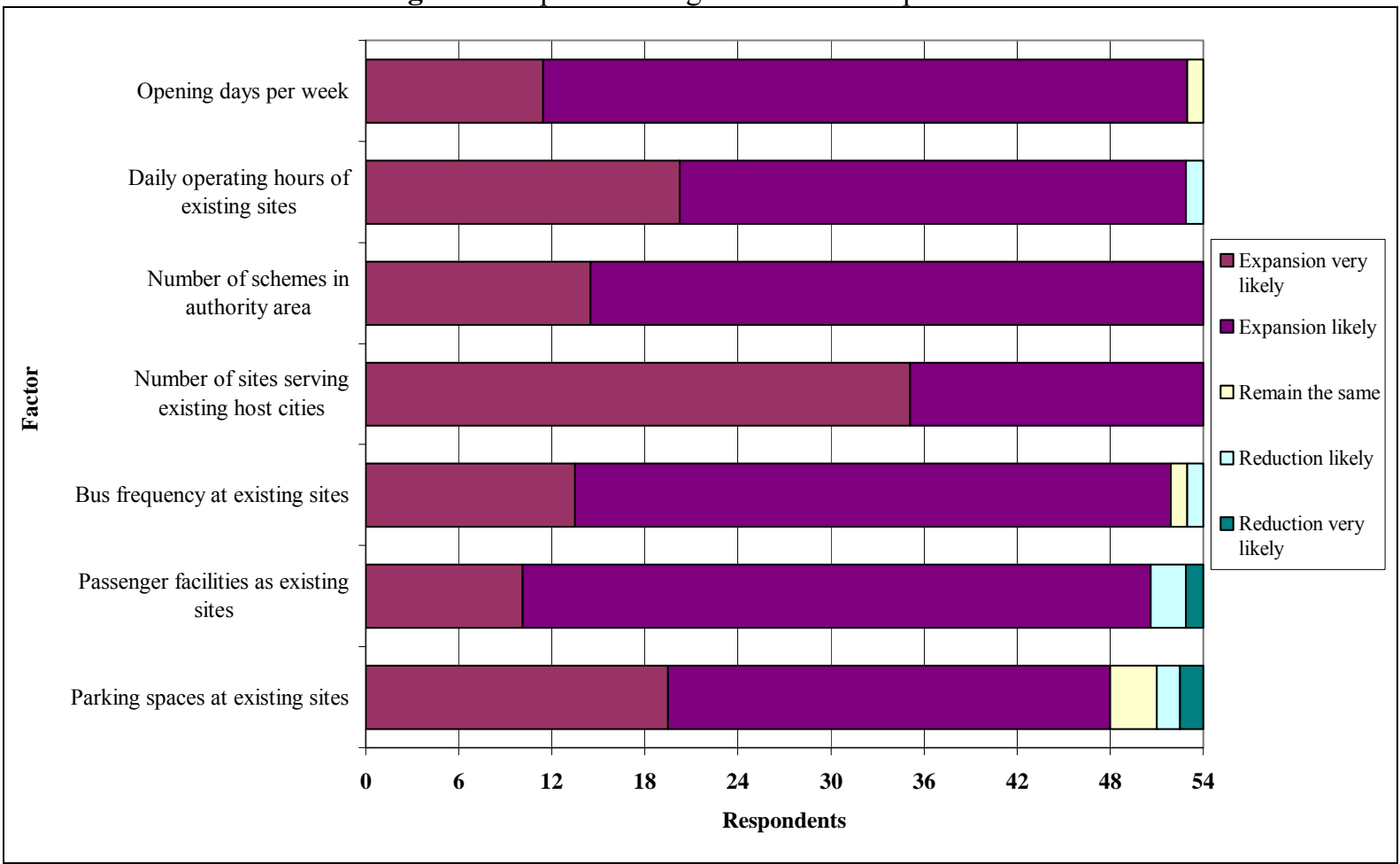

Figure 9 Expected changes in national P\&R provision

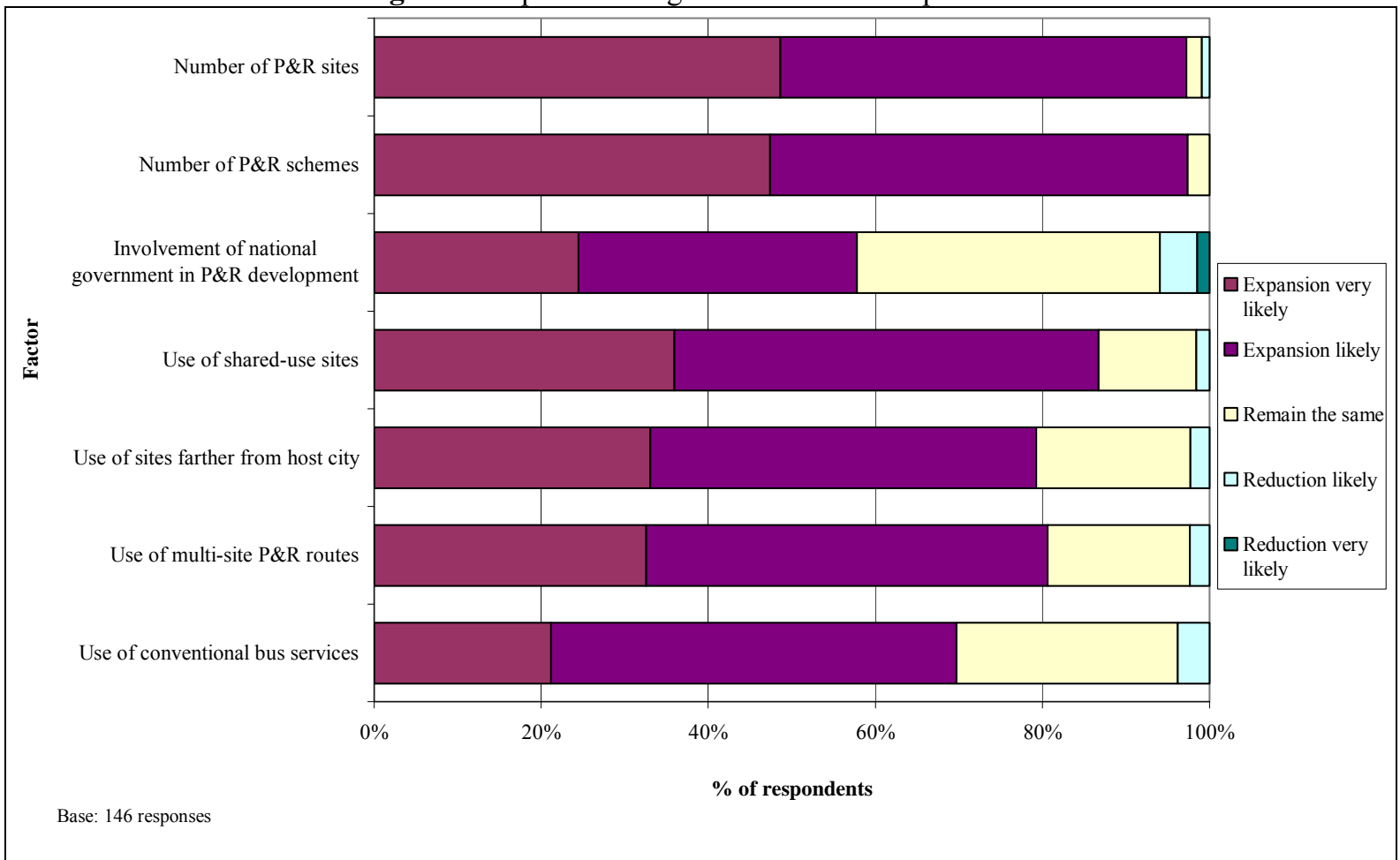

Data on respondents' views of the wider situation may be thought of as somewhat less reliable than those based on actual plans and policy approaches, particularly as the data on the views of authorities without P\&R are incorporated into the analysis. Nevertheless, such views do provide important indications of the feelings towards P\&R as a concept and its development in the UK. Immediately clear from the results (Figure 9), and in parallel to local expectations, is the feeling that the number of both sites and schemes is likely to increase. 
Regarding the direction of $P \& R$ development, the national government became involved in the late-1990s with policy and funding, as outlined above. Yet the conception, implementation and operation of schemes lies within the domain of local authorities. As might be anticipated then, there are more mixed views on a change in the role of the government in P\&R development.

The four variables at the foot of Figure 9 are potential developments to the P\&R concept itself. The way in which P\&R is implemented has changed very little since its first use over 40 years ago. These refinements have the potential to offer efficiency improvements on the current concepts. Shared-use sites are existing car parking that may suffer from low utilisation in some periods - church and stadium car parks are used for this purpose in the US - and depending on the suitability of their location, may be used for P\&R. This not only reduces capital requirements but it may also reduce some of the environmental disbenefits associated with $P \& R$ site construction. The use of sites farther from the host city effectively reduces the car access distance to sites, whilst using multiple sites along a P\&R bus routes may have greater benefits in this regard. The use of conventional bus services to serve P\&R sites would help reduce public transport abstraction.

Even though conventional bus use offers the least disruption to existing service, at least in terms of infrastructure, it received the least favourable response. This may indicate a feeling that the removal of the inherent characteristics of P\&R would diminish its attractiveness. Very high frequencies and high quality buses are characteristics enjoyed by P\&R users and less so by the users of conventional bus services. Indeed, it is factors such as these that elevate the $P \& R$ product and contribute to encouraging modal shift for the latter part of city access trips. Nevertheless, views are more favourable for the other changes, particularly the use of shareduse sites, although this may be expected since it is likely only to affect the facilities offered at the P\&R site.

\section{Conclusions}

At the outset, this paper outlined some of the evidence the traffic effects of P\&R. The situation is unfavourable, particularly when considering VMT effects. The survey reported in this paper sought to understand how this reflected on the views of those who conceive, implement and operate P\&R schemes - policy makers and officers in local government. There is a very significant disparity between their views and that of the evidence. It appears that the basis of this, quite simply, is the view that $\mathrm{P} \& \mathrm{R}$ is effective in reducing congestion, car use and the related externalities. This follows the overall support for measures that promote public transport use. Indeed, many of these measures were actually supported more than a parking charge, the only measure on the scale in the survey that directly utilised the price mechanism. It should be noted however that reference to a parking charge in the survey might have elicited responses based on experience with it in instances where it has probably not been used directly for the purpose of demand management.

It is difficult from the results presented here to draw a line between effectiveness and acceptability and suggest which factor has drawn so much enthusiasm for P\&R. It received similar levels of support on both scales. Nevertheless, other measures considering, for instance, motivations for introducing P\&R beyond strict notions of transport- and economic-related policy goals provided good insights. There seems widespread support for introducing both $\mathrm{P} \& \mathrm{R}$ and other supply-side measures on the basis of the image that they convey of the authority implementing them. This might be anticipated since the political control of local government is democratically elected. Less expected, given the tools available to access national government and private sector funding, was that a funding motivation was considered relatively unimportant in introducing P\&R.

One particularly detrimental effect of $\mathrm{P} \& \mathrm{R}$ is public transport abstraction. This has the potential to significantly offset any VMT savings that result from its use. High levels of route duplication and non-interchangeable ticketing was reported, yet conversely the overall view is that P\&R enhances bus services. Getting the motorist to use P\&R may be a step towards taking the bus for the whole journey. P\&R may also increase awareness and perceptions of viability of bus services. Yet these effects will be long term and arguably more important, in VMT terms at least, is the immediate and direct effect of removing passengers from conventional bus services and encouraging car use for P\&R access trips. This has wider effects also with inter-urban bus routes undoubtedly suffering.

Given the favourable position that has been allocated to $\mathrm{P} \& \mathrm{R}$ within local transport policy, it is unsurprising that it is considered to grow further in the UK. Indeed, this view is almost ubiquitous and is not confined to authorities with existing $\mathrm{P} \& \mathrm{R}$ provision. What is promising about the future is the perceived opportunity to develop the $\mathrm{P} \& \mathrm{R}$ concept and diverge from the model that has sustained since its first use over 40 years ago. 
Governments at all levels that are democratically controlled have always struggled to bridge the gap between effectiveness and acceptability of policies that attempt to reduce absolute levels of car use, and this will continue for the foreseeable future. Strong interdependencies do however exist between effectiveness and acceptability, at least in terms of supply-side 'carrot' policies. They are driven by the need to attract the user to have any significant benefit. Yet these policies, such as P\&R, should be firmly established as capable of delivering real benefits in the first instance. Perhaps more importantly in the context of this work, the full effects of policies need to be understood by those implementing them. This, in turn, points to the role of the national government in setting the correct tone in policy and its interaction with local authorities and their local transport plans.

Potential developments to the concept should be considered a potential way forward. Capitalising on the acceptability that exists for P\&R presents the opportunity to look at how P\&R can be used more effectively. A number of options have been considered here, operating sites farther from the urban core for instance, but there are more and these need to be understood in terms of their effect on VMT and also importantly, how they affect the acceptability of P\&R with both the local authority and the user. 


\section{References}

DETR, 2000. Transport 2010: The 10-Year Plan. London: HMSO.

DoE, 1993. PPG6: Town Centres and Retail Developments July 1993 ed. London: HMSO.

DoE/DoT, 1994. PPG13: Transport. London: HMSO.

Goodwin, P., 1999. Transformation of transport policy in Great Britain. Transportation Research Part A, 33, 655-669.

Ison, S., 2000. Local authority and academic attitudes to urban road pricing: a UK perspective. Transport Policy, 7, 269-277.

Meek, S., Ison, S., and Enoch, M., 2008. Role of bus-based park and ride in the UK: A temporal and evaluative review. Transport Reviews, 28(6), 781-803.

Papoulias, D., and Heggie, I.G., 1976. A Comparative Evaluation of Forecast and Use of Park and Ride in Oxford. Working Paper 22. Transport Studies Unit, University of Oxford.

Parkhurst, G., 1995. Park and Ride: Could it lead to an increase in car traffic? Transport Policy, 2(1), 15-23.

Parkhurst, G., 1999. Environmental Cost-Benefits of Bus-based Park and Ride Systems. Working Paper 1999/4. London: ESRC Transport Studies Unit, University College London.

Parkhurst, G., and Stokes, G., 1994. Park and Ride in Oxford and York: Report of Surveys. Oxford: University of Oxford Transport Studies Unit.

Shaw, J., and Walton, W., 2001. Labour's new trunk-roads policy for England: An emerging Pragmatic Multimodalism? Environment and Planning, 33(6), 1031-1056

TAS Partnership, 2007. Park \& Ride Great Britain. 4th ed. Skipton: TAS Partnership.

White, C.J., 1977. Park and Ride in Oxford and a Survey to Investigate the Possibility of Closing the Botley Road Site. Unpublished Student Project. Department of Geography, University of Reading.

WSA - W.S. Atkins, 1998. The Travel Effects of Park and Ride. Epsom: W.S. Atkins Planning Consultants (for DETR). 